\title{
Review of Hsiang-Ke Chao's Representation and structure in economics: the methodology of econometric models of the consumption function. London: Routledge, 2008, $176 \mathrm{pp}$.
}

\section{CHRISTOPHER L. GILBERT \\ University of Trento}

This volume derives from Chao's 2002 University of Amsterdam doctoral thesis. Chao contrasts the received and the semantic views of theory in economics and comes down clearly in favour of the latter. He illustrates his arguments with discussion of demand theory, the consumption function, and the so-called LSE approach to econometrics. The account is commendably (perhaps overly) concise and is generally clear. However, it betrays both its vintage and its thesis origin. In this review, I discuss Chao's views on structure primarily in relation to demand theory.

The received view sees theory as consisting of a set of abstract axioms plus a set of correspondence principles which link the axiomatic relationships to the world. So-called modern (i.e., pre-behavioural) demand theory appears to conform to this paradigm-the theory consists of a set of axioms defining the relation $\geqslant$ and a correspondence rule which interprets $\geqslant$ in terms of choice. Unfortunately, the remainder of the economics corpus fits the received view less well. The semantic view is not susceptible to such a precise characterization. It relates to a broad collection of less abstract approaches to the role of theory in which theory and structure become closely related concepts. Theory posits a structure, or a range of structures, to which the world corresponds, either isomorphically or by analogy. Models have structure and their structures purport to represent the structure of the worldhence the title of the book.

Models, and hence implicitly also theories, are partial accounts of a complicated reality and therefore necessarily simplify. Model structures can therefore only aspire to being partial representations, in the same way that a road map is, by design, a partial representation of the terrain. Alternative partial representations are possible-road maps and topographical maps offer different representations, each of which has its own validity. Even if it were desirable, an isomorphic correspondence 
between the world and theory would be unattainable and Chao is therefore right in preferring an analogy-based account of the semantic view. However, this leaves open how we establish whether a simple theoretical structure does indeed represent an unknowable and probably complicated structure.

The experimental sciences (not explicitly discussed by Chao) finesse this problem by aligning the world with theory through the creation of controlled environments. By simplifying the world, analogy approaches isomorphism. Economics remains largely non-experimental and the literature Chao discusses is entirely non-experimental. In non-experimental disciplines, whether astrophysics, economics or meteorology, we are obliged to analyze the data generated by 'nature's experiments'.

Chao sees Richard Stone's (1954) paper on the linear expenditure system (LES) as defining the birth of modern demand theory. He quotes Louis Phlips (1983) as stating that it is only once the restrictions imposed by theory have been imposed that an equation relating quantity purchased to income and prices can be recognized as a demand equation: "Economists have realized that a function that does not satisfy the Slutsky conditions is not a demand equation" (Phlips 1983, 56, emphasis in the original). ${ }^{1}$ On Phlips's view, apparently endorsed by Chao, Stone was indeed the first economist to qualify as doing demand theory. The claim is absurd.

Stone made contributions of the first order of importance to demand analysis, but he was continuing the programme initiated by Harold Schultz and set out in the final chapter of his monumental Theory and measurement of demand (1938). Schultz saw himself as building on the work of his teacher Henry Ludwell Moore. The largest part of the empirical analysis in that book takes the form of regressions between appropriately transformed variables (detrended or differenced). The Slutsky condition arrives only later in the book where Schultz remarks: "The attack on this problem need not be wholly empirical" $(1938,599)$. He discusses "difficulties encountered in statistical testing of the theory" (1938, 628-633) in the context of inter-related demand and performs a number of informal tests, comparing estimates of the left and right hand sides of the Slutsky equation. However, he is more concerned with empirically distinguishing between complement and substitute commodities.

\footnotetext{
${ }^{1}$ The assertion is less emphatic in the 1974 first edition of the book.
} 
When Stone (1954) imposed the Slutsky symmetry condition in the LES, his objective was reduction in the number of cross-price elasticities to be estimated, not theory testing. In a previous discussion (Gilbert 1991, 300), I quoted a 1985 letter from Stone in which he wrote: "I introduced the [Slutsky] condition, which could not be expected to hold rigorously for a community of consumers, as a plausible means of greatly reducing the number of constraints to be estimated". Stone was a user and not a tester of theory. It was only later that testing moved centre-stage, once demand theory was taken over by econometricians, perhaps starting with Byron (1970). Subsequently, this was seized upon by the methodologists as the way economic science should proceed.

Both Schultz and Stone saw the role of theory as that of organizing data and structuring research. Schultz states: "[Theory] is, therefore, ideally suited not only for organizing the masses of accumulated data but also for giving coherence to future investigations" (1938, 663). He goes on to remark that quantitative research will make theory more "realistic" (1938, 665). Demand studies employing aggregate data exploit theory by treating aggregate outcomes as if generated by a representative consumer. As both Schultz $(1938,630)$ and Stone realized, households are heterogeneous (to use a current term) and aggregate data would therefore be inappropriate if the objective were to test the preference-based theory. But, as both authors stressed, the same theory may nevertheless be useful in structuring aggregative data.

These considerations reinforce Chao's arguments in favour of the semantic approach. He could perhaps have made these arguments more coherently if he had recognized that the three decades following the publication of Stone (1954) gave too much priority both to the role of the axiomatic preference-based theory of demand and to the informativeness of this theory in relation to aggregative data.

Elsewhere, Chao appears sympathetic towards an entirely empiricist approach to structure. He quotes Gustav Cassel $(1932,81)$ with approval on the law of demand and classifies David Hendry as a closet semantic structuralist. Hendry discusses representation in terms of the congruence of the estimated model with the data generating process (DGP) summarizable in the form $D\left(X_{T}^{1} \mid X_{0}, \theta\right)$ (Hendry and Richard, 1982). Hendry advises a battery of tests, including tests for temporal invariance, in which rejections imply lack of congruence. It is possible that there are alternative congruent relationships in which case non- 
uniqueness may be attained by encompassing tests. Conclusions, of course, remain provisional.

If this were all, it would have to be judged as unsatisfactory. The DGP is itself a construct of the modeller, not least through choice of the sample $\{1, \ldots, T\}$, its frequency, the variables of interest $X$, and the implied level of aggregation at which the problem is studied. Reification of the DGP, on the misleading analogy of Monte Carlo experimentation (where the DGP is well-defined and discoverable), makes representation too simple. Hendry's actual econometric practice (as exemplified in Hendry 1993), results in structures which owe much more to standard economic theory than would be likely to arise through the adoption of a purely black box approach, as for implemented in the 'autometrics' module of the OxMetrics ${ }^{\mathrm{TM}}$ software with which he is associated.

There is an additional consideration. Economics is a profession as well as a science and much of what many economists write is motivated, directly or indirectly, by professional concerns. Hendry's work on the consumption function and the demand for money, discussed by Chao, was related to the forecasting interests of the U.K. Treasury and the Bank of England. Theory is relevant to forecasting, in particular because it may provide guidance as to when forecasts have or may become systematically misleading, but the testing of theory is an incidental concern in that context. The characterization of the DGP is a useful way to describe the forecaster's intermediate objective even if the DGP is itself a construct of the same forecasting exercise.

Chao finishes his account with the conclusion: "Models are representations; and, more importantly, models aim to represent structures" (p. 134). The first clause of this statement is unexceptionable, but the second seems either tautological or incorrect. Models embody structures with the objective of being informative about the world. That does not imply that the model structure is the same as the structure of the world, whatever that might mean. Reference to the DGP confuses this issue since the DGP is a construct of the modeller. It is important, as Hendry emphasizes, that an empirical model provides a satisfactory statistical characterization of the dataset on which it is based. Nevertheless, an affirmative answer to this congruence question leaves open the more difficult epistemological question of whether, and in what way, the model, and hence also the DGP, represents the world. If we are to answer that question, we need to 
match the empirical model with a theoretical conception of the economy.

Wade Hands (2001) argues that it can be misleading to suppose that economic science can be discussed in the same methodological terms as the natural sciences. Of course, the natural sciences are themselves diverse and the same arguments show that the methodologies employed in meteorology and biology differ from those in physics. The principal role of theory in economics is that of organizing experience, including data experience. This is not too different from what happens in meteorology. As in meteorology, forecasting is important and, in that context, theory is important insofar as it is useful in improving forecast accuracy. Truth is another matter. Unlike meteorologists, economists are also involved in policy. In this context, we have to understand why things happen as well as to predict what will happen. This involves stronger invariance requirements. Furthermore, whereas forecasts will generally be generated from a single model, policy discussions may rely on a number of competing (complementary and competitive) structures which focus on different mechanisms and rely on different analogies based on different theoretical perspectives. All of this underlines Chao's rejection of the received view of economic methodology in favour of an analogy-based account of the semantic theory. It also forces acknowledgement of the impossibility of a purely empiricist resolution of the representation problem.

\section{REFERENCES}

Byron, Ray P. 1970. Estimating demand systems under separable utility. Review of Economic Studies, 37: 261-274.

Cassell, Karl Gustav. 1932 [1918]. The theory of social economy. London: Ernest Benn.

Gilbert, Christopher L. 1991. Richard Stone, demand theory and the emergence of modern econometrics. Economic Journal, 101 (405): 288-302.

Hands, D. Wade. 2001. Reflection without rules: economic methodology and contemporary science theory. Cambridge: Cambridge University Press.

Hendry, David F. 1993. Econometrics alchemy or science? Oxford: Blackwell.

Hendry, David F., and Jean-François Richard. 1982. On the formulation of empirical models in dynamic econometrics. Journal of Econometrics, 20 (1): 3-33.

Phlips, Louis. 1983 [1974]. Applied consumption analysis. Amsterdam: North Holland Publishing.

Schultz, Harold. 1938. The theory and measurement of demand. Chicago: Chicago University Press.

Stone, J. Richard N. 1954. Linear expenditure systems and demand analysis: an application to the pattern of British demand. Economic Journal, 64 (255): 511-527. 
Christopher L. Gilbert is professor of econometrics at the University of Trento, in Italy. His research interests include development economics, financial econometrics, and the history and methodology of econometrics.

Contact e-mail: <cgilbert@economia.unitn.it> 